\title{
Impact of COVID-19 outbreak on urology practice in India
}

\section{Mahendra Singh ${ }^{1 *}$, Himanshu Pandey ${ }^{1}$, Prateek Gupta1, Gautam Ram Choudhary ${ }^{1}$, Vipin Tyagi ${ }^{2}$, Vijay Kumar Sarma Madduri ${ }^{1}$ and Nikita Shrivastava ${ }^{1}$}

\author{
${ }^{1}$ Department of Urology, AlIMS, Jodhpur, India \\ ${ }^{2}$ Department of Urology, Sir Ganga Ram Hospital, New Delhi, India
}

\section{Abstract}

Background: The rapid spread of 'Coronavirus Disease 2019' (COVID-19) caused by Severe Acute Respiratory Syndrome Coronavirus-type 2 (SARS-CoV-2) significantly impacted health care facilities all across the globe. To assess impact on urology practice in our country, we developed a questionnaire based on relevant questions in current scenario for information regarding challenges and changes urologists were facing in their practices.

Material and methods: We conducted an online survey to find out the impact of COVID-19 on urology practice in Indian scenario. The questionnaire comprised of total 18 questions, which were relevant to day to day practice.

Results: Total 310 urologists across the India participated and consented to being part of the study. The majority admits change in their practice due to the recent COVID-19 outbreak. The majority admitted to attend fixed numbers of patients per day with prior appointment and to keep detailed records. The majority responded in positive that attendees will not be allowed, opted to wear N-95 mask in OPD, opted to take the relevant history, opted for thermal screening, opted for patients to wear a mask before entering OPD room, opted for using the new prescription at new visit and opted to avoid physical examination unless very necessary. The majority wanted to take consent from the patients that they may get infected by COVID-19 in the hospital and agreed on performing COVID-19 testing for every patient posted for surgery. The majority agreed to assign a separate operation theatre to operate patients with positive COVID-19 test and also preferred open surgery over minimal invasive surgery.

Conclusion: Our survey revealed that the recent pandemic led to significant impacts on urology practice in our country. The urologists working in different setups are facing different challenges in this difficult condition. They have made certain changes in their practice to safely provide effective care to their patients.

\section{More Information}

*Address for Correspondence: Mahendra Singh, Department of Urology, AlIMS, Jodhpur, India, Room no 543, Fifth Floor, Pin 342001, Tel: 9891445049 ;

Email: dr.mahi1118@gmail.com

Submitted: April 26, 2021

Approved: June 17, 2021

Published: June 18, 2021

How to cite this article: Singh M, Pandey $\mathrm{H}$, Gupta P, Choudhary GR, Tyagi V, et al. Impact of COVID-19 outbreak on urology practice in India. Arch Surg Clin Res. 2021; 5: 011-019.

DOI: 10.29328/journal.ascr.1001059

Copyright: @ 2021 Singh M, et al. This is an open access article distributed under the Creative Commons Attribution License, which permits unrestricted use, distribution, and reproduction in any medium, provided the original work is properly cited.

Keywords: COVID-19; Urology; Survey; Practice pattern

A) Check for updates

OPEN ACCESS

\section{Introduction}

The rapid spread of 'Coronavirus Disease 2019' (COVID-19) caused by Severe Acute Respiratory Syndrome Coronavirus-type 2 (SARS-CoV-2) significantly impacted health care facilities all across the globe [1.2]. The disease was declared pandemic on 11 March, 2020 by the World Health Organization (WHO) [2]. In India, it has put a lot of strain to already stretched health care facilities and leads to changes in practice patterns of various specialties including urology [3]. Urology is one of the busiest branches in any hospital dealing with various benign diseases, oncological cases and life-threatening conditions such as renal trauma and obstructive uropathies [3,4]. Few surveys have been conducted on the impact of COVID-19 on urology practice in other countries $[4,5]$. In India, the practice pattern of urologist is quite different from developed countries with urologists working in different set-up such as government hospitals, corporate hospitals and private hospitals [6]. To assess impact on urology practice in our country, we developed a questionnaire based on relevant questions in current scenario for information regarding challenges and changes urologists were facing in their practices. Our aim was not an only collection and analysis of data, but also to find out what a practicing urologist is facing and how he is managing the current situation.

\section{Material and methods}

We conducted an online survey to find out the impact of 
COVID-19 on urology practice in Indian scenario. This study was started after taking approval from the Institutional Ethics Committee. The structured questionnaire was made after discussing with experts and reviewing the current literature available on the impact of COVID-19 on health care services. The questionnaire comprised of total 18 questions, which were relevant to day to day practice. The whole questionnaire is provided in the Supplementary material.

The online survey was primarily shared with various urology groups on social media platforms (WhatsApp, Messages, E-mails, Mobile). We personally contacted and requested our seniors, colleagues and juniors to fill the questionnaire and disseminate if further. After clicking on the shared survey link (PubMed: https://docs.google.com/ forms/d/e/1FAIpQLSeW49MBZoxxnpH5rPggsBZFCCtE7 WIFYmQxEdUprInRtv6e2w/viewform?vc $=0 \& c=0 \& w=1$ ), participants were able to access a webpage containing the questionnaire. Before providing a response, participants were questioned about giving consent for participation in the study. The responses to the survey were only accessible to the investigators. All the collected data were analyzed.

\section{Results}

Total 310 urologists across the India participated and consented to being part of the study. Overall responses to all questions are shown in table 1. A significant portion (292, $\{94.2 \%\})$ admits change in their practice due to the recent COVID-19 outbreak. Two hundred and thirty eight (76.8\%) participants admitted that they are attending fixed numbers of patients per day with prior appointment. There was positive response from 234 (75.5\%) participants to keep detailed records of all patients, attendants and hospital visitors in case contact tracing is required.
Two hundred and sixty two (85.1\%) participants responded in positive that attendees will not be allowed with a patient unless necessary. The majority $(290\{93.6 \%\})$ opted to take the relevant history of fever, respiratory symptoms, travel and contacts of patients before let them enter into OPD (Outpatient Department) room. Two hundred and forty two participants (78.1\%) opted for thermal screening of patients before entering them in OPD room. To sanitize hands of patients before allowing them to OPD room, 262 participants (85.1\%) were agreed. Barring 4 participants, all (306) were agreed that patients should wear a mask before entering OPD room. One hundred and sixty participants (51.7\%) were agreed on using the new prescription at each visit to avoid touching old prescription. Two hundred and eighty participants (90.4\%) responded with yes, that they will try to avoid physical examination unless very necessary. Only 90 (29\%) were agreed on sanitizing of the consultation room before attending next patient. Only118 participants (38.1\%) agreed to maintain unidirectional flow of OPD by maintaining separate entry and exit points.

Two hundred and thirty participants (74.2\%) agreed that they will take consent from the patients that they may get infected by COVID-19 in the hospital or may cause infection to fellow patients if they are asymptomatic carriers. The majority (63.9\%) agreed on performing COVID-19 testing for every patient posted for surgery, whereas the rest agreed to test only suspected cases. Approximately half of the participants (49.7\%) wanted to perform HRCT chest in all patients with positive RT-PCR or antibody test.

The majority (71.6\%) agreed to assign a separate operation theatre to operate patients with positive COVID-19 test. A significant proportion (63.9\%) preferred open surgery over minimal invasive surgery (Laparoscopic/Robotic).

Table 1: Overall responses.

\begin{tabular}{|c|c|c|c|c|c|c|}
\hline \multirow{2}{*}{ Questions } & \multicolumn{2}{|c|}{ Yes } & \multicolumn{2}{|c|}{ No } & \multicolumn{2}{|c|}{ No response } \\
\hline & Number & $\%$ & Number & $\%$ & Number & $\%$ \\
\hline Any change in your practice pattern? & 292 & 94.2 & 16 & 5.1 & 2 & 0.7 \\
\hline Attend patients with prior appointment or will attend fixed number of patients? & 238 & 76.8 & 72 & 23.2 & 0 & 0 \\
\hline Maintain detailed record of all patients, attendants and hospital visitors? & 234 & 75.5 & 74 & 23.9 & 2 & 0.6 \\
\hline Attendee will not be allowed with patients? & 262 & 85.1 & 48 & 14.9 & 0 & 0 \\
\hline Going to take relevant history before entry in OPD room? & 290 & 93.6 & 18 & 5.8 & 2 & 0.6 \\
\hline Thermal screening of patient before entry in OPD room? & 242 & 78.1 & 66 & 21.3 & 2 & 0.6 \\
\hline Sanitizing hands of patients before allowing them to OPD room? & 262 & 85.1 & 46 & 14.3 & 2 & 0.6 \\
\hline Patients should wear a mask before entering OPD room? & 306 & 99.4 & 4 & 0.6 & 0 & 0 \\
\hline Using new prescription at each visit? & 160 & 51.7 & 148 & 47.7 & 2 & 0.6 \\
\hline Avoid physical examination unless very necessary? & 280 & 90.4 & 28 & 9 & 2 & 0.6 \\
\hline Sanitizing of consultation room before attending next patient? & 90 & 29 & 218 & 70.4 & 2 & 0.6 \\
\hline Unidirectional flow of OPD by maintaining separate entry and exit point? & 118 & 38.1 & 190 & 61.3 & 2 & 0.6 \\
\hline Consent will be taken from patient that he/she may get infected by COVID-19? & 230 & 74.2 & 74 & 23.9 & 6 & 1.9 \\
\hline COVID -19 testing for every patient posted for surgery? & 198 & 63.9 & 110 & 35.5 & 2 & 0.6 \\
\hline Perform HRCT chest in all patients with positive RT-PCR or Antibody test for COVID-19? & 154 & 49.7 & 150 & 48.4 & 6 & 1.9 \\
\hline Separate operation theatre to operate patients with positive COVID-19 test? & 222 & 71.6 & 78 & 25.2 & 10 & 3.2 \\
\hline Prefer open surgery over minimal invasive surgery for positive COVID-19 patients? & 198 & 63.9 & 108 & 34.8 & 4 & 1.3 \\
\hline Easily getting good quality PPE? & 190 & 61.3 & 118 & 38.1 & 2 & 0.6 \\
\hline Random sampling of healthcare workers involved in patient care? & 178 & 57.5 & 128 & 41.3 & 4 & 1.2 \\
\hline Repeat RT-PCR test before discharging patients after surgery? & 44 & 14.2 & 260 & 83.9 & 6 & 1.9 \\
\hline
\end{tabular}


Regarding availability of good quality PPE, 61.3\% were satisfied. More than half (57.5\%) preferred random sampling of healthcare workers involved in patient care. Only $14.2 \%$ wanted to repeat RT-PCR test before discharging patients after surgery.

We further stratified the responders in various subgroups on the basis of working setup (Table 2), years of experience (Table 3) and according to age group (Table 4). Among the participants, $140(45.2 \%)$ were private practitioner, 88 (28.4\%) belonged to government set-up and 82 (26.5\%) were working in corporate hospital. The majority of them (138, \{44.5\%\}) have practiced urology for more than 11 years, whereas $82(26.5 \%)$ and 92 (29\%) were in practice for 6-10 years and $\leq 5$ years, respectively. The majority of participants $(142,\{45.8 \%\})$ were $\leq 40$ years, whereas 134 $(43.2 \%)$ and $34(11 \%)$ were in $41-60$ years and $\geq 61$ years age group, respectively.

The majority of responders working in different setup gave almost similar responses to most of the questions barring few. One difference noted was that more urologists (59.1\%) working in the government setup were agreed on maintaining the unidirectional flow of OPD by maintaining separate entry and exit points in comparison to corporate (31.7\%) and private setup (28.6\%). Also, more urologists in government setup (86.3\%) were agreed to do COVID-19 testing for every patient posted for surgery in comparison to corporate (68.3\%) and private setup (47.1\%). One more difference noted that more urologists (36.4\%) working in the government setup were in view of to repeat RT-PCR test before discharging patients after surgery in comparison to corporate $(0 \%)$ and private setup $(8.6 \%)$.

After sub-grouping of participants according to years of experience, the majority of responses to questions were similar except a few. Lesser participants (63.8\%) with experience of more than 11 years agreed that they will take consent from the patients that they may get infected by COVID-19 in the hospital or may cause infection to fellow patients in comparison to participants in practice for 6-10

Table 2: Response on basis of setup.

\begin{tabular}{|c|c|c|c|c|c|c|c|c|c|}
\hline \multirow[t]{2}{*}{ Questions } & \multicolumn{3}{|c|}{ Government (88) } & \multicolumn{3}{|c|}{ Corporate (82) } & \multicolumn{3}{|c|}{ Private (140) } \\
\hline & $\begin{array}{c}\text { yes } \\
\text { n (\%) }\end{array}$ & $\begin{array}{c}\text { No } \\
\text { n (\%) }\end{array}$ & $\begin{array}{c}\text { No response } \\
(\%)\end{array}$ & $\begin{array}{c}\text { Yes } \\
\text { n (\%) }\end{array}$ & \begin{tabular}{|c|} 
No \\
n (\%)
\end{tabular} & $\begin{array}{c}\text { No response } \\
n(\%)\end{array}$ & $\begin{array}{c}\text { yes } \\
\text { n (\%) }\end{array}$ & $\begin{array}{c}\text { No } \\
\text { n (\%) }\end{array}$ & $\begin{array}{c}\text { No response } \\
n(\%)\end{array}$ \\
\hline Any change in your practice pattern? & $\begin{array}{c}82 \\
(93.2)\end{array}$ & $\begin{array}{c}4 \\
(4.5)\end{array}$ & $\begin{array}{c}2 \\
(2.3)\end{array}$ & $\begin{array}{c}80 \\
(97.6)\end{array}$ & $\begin{array}{c}2 \\
(2.4)\end{array}$ & $\begin{array}{c}0 \\
(0)\end{array}$ & $\begin{array}{c}130 \\
(92.9)\end{array}$ & $\begin{array}{c}10 \\
(7.1)\end{array}$ & $\begin{array}{c}0 \\
(0)\end{array}$ \\
\hline Attend patients with prior appointment or will attend fixed number of patients? & $\begin{array}{c}66 \\
(75)\end{array}$ & $\begin{array}{c}22 \\
(25)\end{array}$ & $\begin{array}{c}0 \\
(0)\end{array}$ & $\begin{array}{c}70 \\
(85.4)\end{array}$ & $\begin{array}{c}12 \\
(14.6)\end{array}$ & $\begin{array}{c}0 \\
(0)\end{array}$ & $\begin{array}{c}102 \\
(72.9)\end{array}$ & $\begin{array}{c}38 \\
(27.1)\end{array}$ & $\begin{array}{c}0 \\
(0)\end{array}$ \\
\hline Maintain detailed record of all patients, attendants and hospital visitors? & $\begin{array}{c}60 \\
(68.2)\end{array}$ & $\begin{array}{c}28 \\
(31.8)\end{array}$ & $\begin{array}{c}0 \\
(0)\end{array}$ & $\begin{array}{c}72 \\
(87.8)\end{array}$ & $\begin{array}{c}10 \\
(12.2)\end{array}$ & $\begin{array}{c}0 \\
(0)\end{array}$ & $\begin{array}{c}102 \\
(72.8)\end{array}$ & $\begin{array}{c}36 \\
(25.8)\end{array}$ & $\begin{array}{c}2 \\
(1.4)\end{array}$ \\
\hline Attendee will not be allowed with patients? & $\begin{array}{c}78 \\
(88.6)\end{array}$ & $\begin{array}{c}10 \\
(11.4)\end{array}$ & $\begin{array}{c}0 \\
(0)\end{array}$ & $\begin{array}{c}70 \\
(85.4)\end{array}$ & $\begin{array}{c}12 \\
(14.6)\end{array}$ & $\begin{array}{c}0 \\
(0)\end{array}$ & $\begin{array}{c}114 \\
(81.4)\end{array}$ & $\begin{array}{c}26 \\
(18.6)\end{array}$ & $\begin{array}{c}0 \\
(0)\end{array}$ \\
\hline Going to take relevant history before entry in OPD room? & $\begin{array}{c}76 \\
(86.3)\end{array}$ & $\begin{array}{c}10 \\
(11.4)\end{array}$ & $\begin{array}{c}2 \\
(2.3)\end{array}$ & $\begin{array}{c}76 \\
(92.7)\end{array}$ & $\begin{array}{c}6 \\
(7.3)\end{array}$ & $\begin{array}{c}0 \\
(0)\end{array}$ & $\begin{array}{c}138 \\
(98.6)\end{array}$ & $\begin{array}{c}2 \\
(1.4)\end{array}$ & $\begin{array}{c}0 \\
(0)\end{array}$ \\
\hline Thermal screening of patient before entry in OPD room? & $\begin{array}{c}66 \\
(75)\end{array}$ & $\begin{array}{c}20 \\
(22.7)\end{array}$ & $\begin{array}{c}2 \\
(2.3)\end{array}$ & $\begin{array}{c}64 \\
(78)\end{array}$ & $\begin{array}{c}18 \\
(22)\end{array}$ & $\begin{array}{c}0 \\
(0)\end{array}$ & $\begin{array}{l}112 \\
(80)\end{array}$ & $\begin{array}{c}28 \\
(20)\end{array}$ & $\begin{array}{c}0 \\
(0)\end{array}$ \\
\hline Sanitizing hands of patients before allowing them to OPD room? & $\begin{array}{c}66 \\
(75)\end{array}$ & $\begin{array}{c}20 \\
(22.7)\end{array}$ & $\begin{array}{c}2 \\
(2.3)\end{array}$ & $\begin{array}{c}68 \\
(83)\end{array}$ & $\begin{array}{c}14 \\
(17)\end{array}$ & $\begin{array}{c}0 \\
(0)\end{array}$ & $\begin{array}{c}128 \\
(91.4)\end{array}$ & $\begin{array}{c}12 \\
(8.6)\end{array}$ & $\begin{array}{c}0 \\
(0)\end{array}$ \\
\hline Patients should wear a mask before entering OPD room? & $\begin{array}{c}84 \\
(95.5)\end{array}$ & $\begin{array}{c}4 \\
(4.5)\end{array}$ & $\begin{array}{c}0 \\
(0)\end{array}$ & $\begin{array}{c}82 \\
(100)\end{array}$ & $\begin{array}{c}0 \\
(0)\end{array}$ & $\begin{array}{c}0 \\
(0)\end{array}$ & $\begin{array}{c}140 \\
(100)\end{array}$ & $\begin{array}{c}0 \\
(0)\end{array}$ & $\begin{array}{c}0 \\
(0)\end{array}$ \\
\hline Using new prescription at each visit? & $\begin{array}{c}48 \\
(54.5)\end{array}$ & $\begin{array}{c}38 \\
(43.2))\end{array}$ & $\begin{array}{c}2 \\
(2.3)\end{array}$ & $\begin{array}{c}52 \\
(63.4)\end{array}$ & $\begin{array}{c}30 \\
(36.6)\end{array}$ & $\begin{array}{c}0 \\
(0)\end{array}$ & $\begin{array}{c}60 \\
(42.9)\end{array}$ & $\begin{array}{c}80 \\
(57.1)\end{array}$ & $\begin{array}{c}0 \\
(0)\end{array}$ \\
\hline Avoid physical examination unless very necessary? & $\begin{array}{c}82 \\
(93.2)\end{array}$ & $\begin{array}{c}4 \\
(4.5)\end{array}$ & $\begin{array}{c}2 \\
(2.3)\end{array}$ & $\begin{array}{c}80 \\
(87.6)\end{array}$ & $\begin{array}{c}2 \\
(2.4)\end{array}$ & $\begin{array}{c}0 \\
(0)\end{array}$ & $\begin{array}{c}118 \\
(84.3)\end{array}$ & $\begin{array}{c}22 \\
(15.7)\end{array}$ & $\begin{array}{c}0 \\
(0)\end{array}$ \\
\hline Sanitizing of consultation room before attending next patient? & $\begin{array}{c}28 \\
(31.8)\end{array}$ & $\begin{array}{c}58 \\
(65.9)\end{array}$ & $\begin{array}{c}2 \\
(2.3)\end{array}$ & $\begin{array}{c}20 \\
(24.4)\end{array}$ & $\begin{array}{c}62 \\
(75.6)\end{array}$ & $\begin{array}{c}0 \\
(0)\end{array}$ & $\begin{array}{c}42 \\
(30)\end{array}$ & $\begin{array}{c}98 \\
(70)\end{array}$ & $\begin{array}{c}0 \\
(0)\end{array}$ \\
\hline Unidirectional flow of OPD by maintaining separate entry and exit point? & $\begin{array}{c}52 \\
(59.1)\end{array}$ & $\begin{array}{c}34 \\
(38.6)\end{array}$ & $\begin{array}{c}2 \\
(2.3)\end{array}$ & $\begin{array}{c}26 \\
(31.7)\end{array}$ & $\begin{array}{c}56 \\
(68.3)\end{array}$ & $\begin{array}{c}0 \\
(0)\end{array}$ & $\begin{array}{c}40 \\
(28.6)\end{array}$ & $\begin{array}{c}100 \\
(71.4)\end{array}$ & $\begin{array}{c}0 \\
(0)\end{array}$ \\
\hline Consent will be taken from patient that he/she may get infected by COVID-19? & $\begin{array}{c}72 \\
(81.8)\end{array}$ & $\begin{array}{c}12 \\
(13.6)\end{array}$ & $\begin{array}{c}4 \\
(4.6)\end{array}$ & $\begin{array}{c}62 \\
(75.6)\end{array}$ & $\begin{array}{c}18 \\
(22)\end{array}$ & $\begin{array}{c}2 \\
(2.4)\end{array}$ & $\begin{array}{c}96 \\
(68.6)\end{array}$ & $\begin{array}{c}44 \\
(31.4)\end{array}$ & $\begin{array}{c}0 \\
(0)\end{array}$ \\
\hline COVID -19 testing for every patient posted for surgery? & $\begin{array}{c}76 \\
(86.3)\end{array}$ & $\begin{array}{c}10 \\
(11.4)\end{array}$ & $\begin{array}{c}2 \\
(2.3)\end{array}$ & $\begin{array}{c}56 \\
(68.3)\end{array}$ & $\begin{array}{c}26 \\
(31.7)\end{array}$ & $\begin{array}{c}0 \\
(0)\end{array}$ & $\begin{array}{c}66 \\
(47.1)\end{array}$ & $\begin{array}{c}74 \\
(52.9)\end{array}$ & $\begin{array}{c}0 \\
(0)\end{array}$ \\
\hline $\begin{array}{l}\text { Perform HRCT chest in all patients with positive RT-PCR or Antibody test for } \\
\text { COVID-19? }\end{array}$ & $\begin{array}{c}38 \\
(43.2)\end{array}$ & $\begin{array}{c}50 \\
(56.8)\end{array}$ & $\begin{array}{c}0 \\
(0)\end{array}$ & $\begin{array}{c}56 \\
(68.3)\end{array}$ & $\begin{array}{c}26 \\
(31.7)\end{array}$ & $\begin{array}{c}0 \\
(0)\end{array}$ & $\begin{array}{c}60 \\
(42.9)\end{array}$ & $\begin{array}{c}74 \\
(52.9)\end{array}$ & $\begin{array}{c}6 \\
(4.2)\end{array}$ \\
\hline Separate operation theatre to operate patients with positive COVID-19 test? & $\begin{array}{c}68 \\
(77.3)\end{array}$ & $\begin{array}{c}20 \\
(22.7)\end{array}$ & $\begin{array}{c}0 \\
(0)\end{array}$ & $\begin{array}{c}62 \\
(75.6)\end{array}$ & $\begin{array}{c}18 \\
(22)\end{array}$ & $\begin{array}{c}2 \\
(2.4)\end{array}$ & $\begin{array}{c}92 \\
(65.7)\end{array}$ & $\begin{array}{c}40 \\
(28.6)\end{array}$ & $\begin{array}{c}8 \\
(5.7)\end{array}$ \\
\hline $\begin{array}{l}\text { Prefer open surgery over minimal invasive surgery for positive COVID-19 } \\
\text { patients? }\end{array}$ & $\begin{array}{c}50 \\
(56.8)\end{array}$ & $\begin{array}{c}38 \\
(43.2)\end{array}$ & $\begin{array}{c}0 \\
(0)\end{array}$ & $\begin{array}{c}56 \\
(68.3)\end{array}$ & $\begin{array}{c}24 \\
(29.3)\end{array}$ & $\begin{array}{c}2 \\
(2.4)\end{array}$ & $\begin{array}{c}92 \\
(65.7)\end{array}$ & $\begin{array}{c}46 \\
(32.9)\end{array}$ & $\begin{array}{c}2 \\
(1.4)\end{array}$ \\
\hline Easily getting good quality PPE? & $\begin{array}{c}48 \\
(54.5)\end{array}$ & $\begin{array}{c}38 \\
(43.2)\end{array}$ & $\begin{array}{c}2 \\
(2.3)\end{array}$ & $\begin{array}{c}50 \\
(61)\end{array}$ & $\begin{array}{c}32 \\
(39)\end{array}$ & $\begin{array}{c}0 \\
(0)\end{array}$ & $\begin{array}{c}92 \\
(65.7)\end{array}$ & $\begin{array}{c}48 \\
(34.3)\end{array}$ & $\begin{array}{c}0 \\
(0)\end{array}$ \\
\hline Random sampling of healthcare workers involved in patient care? & $\begin{array}{c}46 \\
(52.3)\end{array}$ & $\begin{array}{c}42 \\
(47.7)\end{array}$ & $\begin{array}{c}0 \\
(0)\end{array}$ & $\begin{array}{c}50 \\
(61)\end{array}$ & $\begin{array}{c}30 \\
(36.6)\end{array}$ & $\begin{array}{c}2 \\
(2.4)\end{array}$ & $\begin{array}{c}82 \\
(58.6)\end{array}$ & $\begin{array}{c}56 \\
(40)\end{array}$ & $\begin{array}{c}2 \\
(1.4)\end{array}$ \\
\hline Repeat RT-PCR test before discharging patients after surgery? & $\begin{array}{c}32 \\
(36.4)\end{array}$ & $\begin{array}{c}52 \\
(59)\end{array}$ & $\begin{array}{c}4 \\
(4.6)\end{array}$ & $\begin{array}{c}0 \\
(0)\end{array}$ & $\begin{array}{c}82 \\
(100)\end{array}$ & $\begin{array}{c}0 \\
(0)\end{array}$ & $\begin{array}{c}12 \\
(8.6)\end{array}$ & $\begin{array}{l}126 \\
(90)\end{array}$ & $\begin{array}{c}2 \\
(1.4)\end{array}$ \\
\hline
\end{tabular}




\begin{tabular}{|c|c|c|c|c|c|c|c|c|c|}
\hline \multirow[b]{2}{*}{ Questions } & \multicolumn{3}{|c|}{$<5$ YEARS $(90)$} & \multicolumn{3}{|c|}{6 to 10 years $(82)$} & \multicolumn{3}{|c|}{$\geq 11$ years $(138)$} \\
\hline & $\begin{array}{c}\text { yes } \\
\text { n (\%) }\end{array}$ & $\begin{array}{c}\text { No } \\
\text { n (\%) }\end{array}$ & $\begin{array}{l}\text { No response } \\
(\%)\end{array}$ & $\begin{array}{c}\text { Yes } \\
\text { n (\%) }\end{array}$ & $\begin{array}{c}\text { No } \\
n(\%)\end{array}$ & $\begin{array}{l}\text { No response } \\
n(\%)\end{array}$ & $\begin{array}{c}\text { yes } \\
\mathrm{n}(\%)\end{array}$ & $\begin{array}{c}\text { No } \\
n(\%)\end{array}$ & $\begin{array}{c}\text { No response } \\
n(\%)\end{array}$ \\
\hline $\begin{array}{l}\text { Any change in your practice } \\
\text { pattern? }\end{array}$ & $\begin{array}{c}86 \\
(95.6)\end{array}$ & $\begin{array}{c}4 \\
(4.4)\end{array}$ & $\begin{array}{c}0 \\
(0 \%)\end{array}$ & $\begin{array}{c}74 \\
(90.3)\end{array}$ & $\begin{array}{c}6 \\
(7.3)\end{array}$ & $\begin{array}{c}2 \\
(2.4)\end{array}$ & $\begin{array}{c}132 \\
(95.7)\end{array}$ & $\begin{array}{c}6 \\
(4.3)\end{array}$ & $\begin{array}{c}0 \\
(0 \%)\end{array}$ \\
\hline $\begin{array}{l}\text { Attend patients with prior } \\
\text { appointment or will attend fixed } \\
\text { number of patients? }\end{array}$ & $\begin{array}{c}68 \\
(75.6)\end{array}$ & $\begin{array}{c}22 \\
(24.4)\end{array}$ & $\begin{array}{c}0 \\
(0 \%)\end{array}$ & $\begin{array}{c}56 \\
(68.3)\end{array}$ & $\begin{array}{c}26 \\
(31.7)\end{array}$ & $\begin{array}{c}0 \\
(0 \%)\end{array}$ & $\begin{array}{c}114 \\
(82.6)\end{array}$ & $\begin{array}{c}24 \\
(17.4)\end{array}$ & $\begin{array}{c}0 \\
(0 \%)\end{array}$ \\
\hline $\begin{array}{l}\text { Maintain detailed record of all } \\
\text { patients, attendants and hospital } \\
\text { visitors? }\end{array}$ & $\begin{array}{l}72 \\
(80)\end{array}$ & $\begin{array}{c}18 \\
(20)\end{array}$ & $\begin{array}{c}0 \\
(0 \%)\end{array}$ & $\begin{array}{c}64 \\
(78.1)\end{array}$ & $\begin{array}{c}18 \\
(21.9)\end{array}$ & $\begin{array}{c}0 \\
(0 \%)\end{array}$ & $\begin{array}{c}98 \\
(71)\end{array}$ & $\begin{array}{c}38 \\
(27.5)\end{array}$ & $\begin{array}{c}2 \\
(1.5)\end{array}$ \\
\hline $\begin{array}{l}\text { Attendee will not be allowed with } \\
\text { patients? }\end{array}$ & $\begin{array}{c}80 \\
(88.9)\end{array}$ & $\begin{array}{c}10 \\
(11.1)\end{array}$ & $\begin{array}{c}0 \\
(0 \%)\end{array}$ & $\begin{array}{c}70 \\
(85.4)\end{array}$ & $\begin{array}{c}12 \\
(14.6)\end{array}$ & $\begin{array}{c}0 \\
(0 \%)\end{array}$ & $\begin{array}{c}112 \\
(81.2)\end{array}$ & $\begin{array}{c}26 \\
(18.8)\end{array}$ & $\begin{array}{c}0 \\
(0 \%)\end{array}$ \\
\hline $\begin{array}{l}\text { Going to take relevant history before } \\
\text { entry in OPD room? }\end{array}$ & $\begin{array}{c}86 \\
(95.6)\end{array}$ & $\begin{array}{c}2 \\
(2.2)\end{array}$ & $\begin{array}{c}2 \\
(2.2)\end{array}$ & $\begin{array}{c}76 \\
(92.7)\end{array}$ & $\begin{array}{c}6 \\
(7.3)\end{array}$ & $\begin{array}{c}0 \\
(0 \%)\end{array}$ & $\begin{array}{c}128 \\
(92.8)\end{array}$ & $\begin{array}{c}10 \\
(7.2)\end{array}$ & $\begin{array}{c}0 \\
(0 \%)\end{array}$ \\
\hline $\begin{array}{l}\text { Thermal screening of patient before } \\
\text { entry in OPD room? }\end{array}$ & $\begin{array}{c}70 \\
(77.8)\end{array}$ & $\begin{array}{c}18 \\
(20)\end{array}$ & $\begin{array}{c}2 \\
(2.2)\end{array}$ & $\begin{array}{c}72 \\
(87.8)\end{array}$ & $\begin{array}{c}10 \\
(12.2)\end{array}$ & $\begin{array}{c}0 \\
(0 \%)\end{array}$ & $\begin{array}{c}100 \\
(72.5)\end{array}$ & $\begin{array}{c}38 \\
(27.5)\end{array}$ & $\begin{array}{c}0 \\
(0 \%)\end{array}$ \\
\hline $\begin{array}{l}\text { Sanitizing hands of patients before } \\
\text { allowing them to OPD room? }\end{array}$ & $\begin{array}{c}66 \\
(73.4)\end{array}$ & $\begin{array}{c}22 \\
(24.4)\end{array}$ & $\begin{array}{c}2 \\
(2.2)\end{array}$ & $\begin{array}{c}70 \\
(85.4)\end{array}$ & $\begin{array}{c}12 \\
(14.6)\end{array}$ & $\begin{array}{c}0 \\
(0 \%)\end{array}$ & $\begin{array}{c}126 \\
(91.3)\end{array}$ & $\begin{array}{c}12 \\
(8.7)\end{array}$ & $\begin{array}{c}0 \\
(0 \%)\end{array}$ \\
\hline $\begin{array}{l}\text { Patients should wear a mask before } \\
\text { entering OPD room? }\end{array}$ & $\begin{array}{c}90 \\
(100 \%)\end{array}$ & $\begin{array}{c}0 \\
(0 \%)\end{array}$ & $\begin{array}{c}0 \\
(0 \%)\end{array}$ & $\begin{array}{c}78 \\
(95.1)\end{array}$ & $\begin{array}{c}4 \\
(4.9)\end{array}$ & $\begin{array}{c}0 \\
(0 \%)\end{array}$ & $\begin{array}{c}138 \\
(100)\end{array}$ & $\begin{array}{c}0 \\
(0)\end{array}$ & $\begin{array}{c}0 \\
(0 \%)\end{array}$ \\
\hline $\begin{array}{c}\text { Using new prescription at each } \\
\text { visit? }\end{array}$ & $\begin{array}{c}46 \\
(51.1 \%)\end{array}$ & $\begin{array}{c}42 \\
(46.7 \%)\end{array}$ & $\begin{array}{c}2 \\
(2.2)\end{array}$ & $\begin{array}{c}38 \\
(46.3)\end{array}$ & $\begin{array}{c}44 \\
(53.7)\end{array}$ & $\begin{array}{c}0 \\
(0 \%)\end{array}$ & $\begin{array}{c}76 \\
(55.1)\end{array}$ & $\begin{array}{c}62 \\
(44.9)\end{array}$ & $\begin{array}{c}0 \\
(0 \%)\end{array}$ \\
\hline $\begin{array}{l}\text { Avoid physical examination unless } \\
\text { very necessary? }\end{array}$ & $\begin{array}{c}86 \\
(95.6)\end{array}$ & $\begin{array}{c}2 \\
(2.2)\end{array}$ & $\begin{array}{c}2 \\
(2.2)\end{array}$ & $\begin{array}{c}74 \\
(90.3)\end{array}$ & $\begin{array}{c}8 \\
(9.7)\end{array}$ & $\begin{array}{c}0 \\
(0 \%)\end{array}$ & $\begin{array}{l}120 \\
(87)\end{array}$ & $\begin{array}{c}18 \\
(13)\end{array}$ & $\begin{array}{c}0 \\
(0 \%)\end{array}$ \\
\hline $\begin{array}{l}\text { Sanitizing of consultation room } \\
\text { before attending next patient? }\end{array}$ & $\begin{array}{c}26 \\
(28.9)\end{array}$ & $\begin{array}{c}62 \\
(68.9)\end{array}$ & $\begin{array}{c}2 \\
(2.2)\end{array}$ & $\begin{array}{c}16 \\
(19.5)\end{array}$ & $\begin{array}{c}66 \\
(80.5)\end{array}$ & $\begin{array}{c}0 \\
(0 \%)\end{array}$ & $\begin{array}{c}48 \\
(34.8)\end{array}$ & $\begin{array}{c}90 \\
(65.2)\end{array}$ & $\begin{array}{c}0 \\
(0 \%)\end{array}$ \\
\hline $\begin{array}{c}\text { Unidirectional flow of OPD by } \\
\text { maintaining separate entry and exit } \\
\text { point? }\end{array}$ & $\begin{array}{c}40 \\
(44.5)\end{array}$ & $\begin{array}{c}48 \\
(53.3 \%)\end{array}$ & $\begin{array}{c}2 \\
(2.2)\end{array}$ & $\begin{array}{c}34 \\
(41.5)\end{array}$ & $\begin{array}{c}48 \\
(58.5)\end{array}$ & $\begin{array}{c}0 \\
(0 \%)\end{array}$ & $\begin{array}{c}44 \\
(31.9)\end{array}$ & $\begin{array}{c}94 \\
(68.1)\end{array}$ & $\begin{array}{c}0 \\
(0 \%)\end{array}$ \\
\hline $\begin{array}{l}\text { Consent will be taken from patient } \\
\text { that he/she may get infected by } \\
\text { COVID-19? }\end{array}$ & $\begin{array}{c}76 \\
(84.5)\end{array}$ & $\begin{array}{c}12 \\
(13.3 \%)\end{array}$ & $\begin{array}{c}2 \\
(2.2)\end{array}$ & $\begin{array}{c}66 \\
(80.5)\end{array}$ & $\begin{array}{c}16 \\
(19.5)\end{array}$ & $\begin{array}{c}0 \\
(0 \%)\end{array}$ & $\begin{array}{c}88 \\
(63.8)\end{array}$ & $\begin{array}{c}46 \\
(33.3)\end{array}$ & $\begin{array}{c}4 \\
(2.9)\end{array}$ \\
\hline $\begin{array}{l}\text { COVID -19 testing for every patient } \\
\text { posted for surgery? }\end{array}$ & $\begin{array}{c}58 \\
(64.5)\end{array}$ & $\begin{array}{c}30 \\
(33.3)\end{array}$ & $\begin{array}{c}2 \\
(2.2)\end{array}$ & $\begin{array}{c}54 \\
(65.9)\end{array}$ & $\begin{array}{c}28 \\
(34.1)\end{array}$ & $\begin{array}{c}0 \\
(0 \%)\end{array}$ & $\begin{array}{c}86 \\
(62.3)\end{array}$ & $\begin{array}{c}52 \\
(37.7)\end{array}$ & $\begin{array}{c}0 \\
(0 \%)\end{array}$ \\
\hline $\begin{array}{c}\text { Perform HRCT chest in all patients } \\
\text { with positive RT-PCR or Antibody } \\
\text { test for COVID-19? }\end{array}$ & $\begin{array}{c}42 \\
(46.7)\end{array}$ & $\begin{array}{c}48 \\
(53.3)\end{array}$ & $\begin{array}{c}0 \\
(0 \%)\end{array}$ & $\begin{array}{c}42 \\
(51.3)\end{array}$ & $\begin{array}{c}38 \\
(46.3)\end{array}$ & $\begin{array}{c}2 \\
(2.4)\end{array}$ & $\begin{array}{c}70 \\
(50.7)\end{array}$ & $\begin{array}{c}64 \\
(46.4)\end{array}$ & $\begin{array}{c}4 \\
(2.9)\end{array}$ \\
\hline $\begin{array}{l}\text { Separate operation theatre to } \\
\text { operate patients with positive } \\
\text { COVID-19 test? }\end{array}$ & $\begin{array}{c}62 \\
(68.9)\end{array}$ & $\begin{array}{c}26 \\
(28.9)\end{array}$ & $\begin{array}{c}2 \\
(2.2)\end{array}$ & $\begin{array}{c}68 \\
(83)\end{array}$ & $\begin{array}{c}12 \\
(14.6)\end{array}$ & $\begin{array}{c}2 \\
(2.4)\end{array}$ & $\begin{array}{c}92 \\
(66.7)\end{array}$ & $\begin{array}{c}40 \\
(2.9)\end{array}$ & $\begin{array}{c}6 \\
(4.4)\end{array}$ \\
\hline $\begin{array}{l}\text { Prefer open surgery over minimal } \\
\text { invasive surgery for positive } \\
\text { COVID-19 patients? }\end{array}$ & $\begin{array}{c}62 \\
(68.9)\end{array}$ & $\begin{array}{c}24 \\
(26.7)\end{array}$ & $\begin{array}{c}4 \\
(4.4)\end{array}$ & $\begin{array}{c}42 \\
(51.3)\end{array}$ & $\begin{array}{c}40 \\
(48.7)\end{array}$ & $\begin{array}{c}0 \\
(0 \%)\end{array}$ & $\begin{array}{c}94 \\
(68.1)\end{array}$ & $\begin{array}{c}44 \\
(31.9)\end{array}$ & $\begin{array}{c}0 \\
(0 \%)\end{array}$ \\
\hline Easily getting good quality PPE? & $\begin{array}{c}32 \\
(35.6)\end{array}$ & $\begin{array}{c}56 \\
(62.2)\end{array}$ & $\begin{array}{c}2 \\
(2.2)\end{array}$ & $\begin{array}{c}56 \\
(68.3)\end{array}$ & $\begin{array}{c}26 \\
(31.7)\end{array}$ & $\begin{array}{c}0 \\
(0 \%)\end{array}$ & $\begin{array}{c}102 \\
(73.9)\end{array}$ & $\begin{array}{c}36 \\
(26.1)\end{array}$ & $\begin{array}{c}0 \\
(0 \%)\end{array}$ \\
\hline $\begin{array}{l}\text { Random sampling of healthcare } \\
\text { workers involved in patient care? }\end{array}$ & $\begin{array}{c}54 \\
(60)\end{array}$ & $\begin{array}{c}32 \\
(35.6)\end{array}$ & $\begin{array}{c}4 \\
(4.4)\end{array}$ & $\begin{array}{c}36 \\
(43.9)\end{array}$ & $\begin{array}{c}46 \\
(56.1)\end{array}$ & $\begin{array}{c}0 \\
(0 \%)\end{array}$ & $\begin{array}{c}88 \\
(63.8)\end{array}$ & $\begin{array}{c}50 \\
(36.2)\end{array}$ & $\begin{array}{c}0 \\
(0 \%)\end{array}$ \\
\hline $\begin{array}{c}\text { Repeat RT-PCR test before } \\
\text { discharging patients after surgery? }\end{array}$ & $\begin{array}{c}14 \\
(15.6)\end{array}$ & $\begin{array}{c}76 \\
(84.4)\end{array}$ & $\begin{array}{c}0 \\
(0 \%)\end{array}$ & $\begin{array}{c}16 \\
(19.5)\end{array}$ & $\begin{array}{c}66 \\
(80.5)\end{array}$ & $\begin{array}{c}0 \\
(0 \%)\end{array}$ & $\begin{array}{c}14 \\
(10.2)\end{array}$ & $\begin{array}{c}118 \\
(85.5)\end{array}$ & $\begin{array}{c}6 \\
(4.3)\end{array}$ \\
\hline
\end{tabular}

years $(80.5 \%)$ and $\leq 5$ years $(84.5 \%)$. The participants with $\leq 5$ years experience $(68.9 \%)$ and $\geq 11$ years $(68.1 \%)$ experience preferred open surgery over minimal invasive surgery in comparison to participants with 6-10 years experience (51.3\%). Only, 35.6\% with experience of $\leq 5$ years were easily getting good quality PPE, whereas $68.3 \%$ and $73.9 \%$ were getting them easily with 6-10 years experience and $\geq 11$ years experience, respectively.

Assessment of responses after dividing participants according age group, most answers were not having too much of a difference. One difference we found that the majority $(88.2 \%)$ in the age group of more than 61 years agreed on using the new prescription at each visit to avoid touching old prescription in comparison to $47.9 \%$ in $\leq 40$ years and 46.3 in 41-60 years age group. The senior most groups were more agreed with the sanitizing of the consultation room before attending next patient and also preferred open surgery over minimal invasive surgery. The senior most were also getting PPE easily in comparison to other and also more numbers in them opted for random sampling of healthcare workers involved in patient care, but lesser numbers of seniors agreed regarding obtaining a consent from the patients that they may get infected or may cause infection to others.

As shown in table 5, one hundred and ninety eight participants were using N-95 masks in out-patient departments (OPD) and 60 were using triple layer masks. Forty-eight participants were willing to use either triple layer or N-95 and don't have any preference. There was not too much difference regarding use of the masks according to working setups, but participants with $\leq 5$ years experience 
Table 4: Response according to age groups.

\begin{tabular}{|c|c|c|c|c|c|c|c|c|c|}
\hline \multirow[b]{2}{*}{ Questions } & \multicolumn{3}{|c|}{$\leq 40$ years $(142)$} & \multicolumn{3}{|c|}{$41-60$ years $(134)$} & \multicolumn{3}{|c|}{$\geq 61$ years $(34)$} \\
\hline & $\begin{array}{c}\text { yes } \\
\text { n (\%) }\end{array}$ & $\begin{array}{c}\text { No } \\
n(\%)\end{array}$ & $\begin{array}{c}\text { No response } \\
(\%)\end{array}$ & $\begin{array}{c}\text { Yes } \\
\mathrm{n}(\%)\end{array}$ & $\begin{array}{l}\text { No } \\
n(\%)\end{array}$ & $\begin{array}{c}\text { No response } \\
n(\%)\end{array}$ & $\begin{array}{c}\text { yes } \\
\text { n (\%) }\end{array}$ & $\begin{array}{c}\text { No } \\
\text { n (\%) }\end{array}$ & $\begin{array}{l}\text { No response } \\
n(\%)\end{array}$ \\
\hline Any change in your practice pattern? & $\begin{array}{c}134 \\
(94.4)\end{array}$ & $\begin{array}{c}6 \\
(4.2)\end{array}$ & $\begin{array}{c}2 \\
(1.4)\end{array}$ & $\begin{array}{c}126 \\
(94.1)\end{array}$ & $\begin{array}{c}8 \\
(5.9)\end{array}$ & $\begin{array}{c}0 \\
(0)\end{array}$ & $\begin{array}{c}32 \\
(94.1)\end{array}$ & $\begin{array}{c}2 \\
(5.9)\end{array}$ & $\begin{array}{c}0 \\
(0)\end{array}$ \\
\hline $\begin{array}{l}\text { Attend patients with prior appointment or will attend fixed } \\
\text { number of patients? }\end{array}$ & $\begin{array}{c}106 \\
(74.7)\end{array}$ & $\begin{array}{c}36 \\
(25.3)\end{array}$ & $\begin{array}{c}0 \\
(0)\end{array}$ & $\begin{array}{c}104 \\
(77.6)\end{array}$ & $\begin{array}{c}30 \\
(22.4)\end{array}$ & $\begin{array}{c}0 \\
(0)\end{array}$ & $\begin{array}{c}28 \\
(82.4)\end{array}$ & $\begin{array}{c}6 \\
(17.6)\end{array}$ & $\begin{array}{c}0 \\
(0)\end{array}$ \\
\hline $\begin{array}{l}\text { Maintain detailed record of all patients, attendants and } \\
\text { hospital visitors? }\end{array}$ & $\begin{array}{c}112 \\
(78.9)\end{array}$ & $\begin{array}{c}30 \\
(21.1)\end{array}$ & $\begin{array}{c}0 \\
(0)\end{array}$ & $\begin{array}{c}96 \\
(71.7)\end{array}$ & $\begin{array}{c}38 \\
(28,3)\end{array}$ & $\begin{array}{c}0 \\
(0)\end{array}$ & $\begin{array}{c}28 \\
(76.5)\end{array}$ & $\begin{array}{c}6 \\
(17.6)\end{array}$ & $\begin{array}{c}2 \\
(5.9)\end{array}$ \\
\hline Attendee will not be allowed with patients? & $\begin{array}{c}122 \\
(85.9)\end{array}$ & $\begin{array}{c}20 \\
(14.1)\end{array}$ & $\begin{array}{c}0 \\
(0)\end{array}$ & $\begin{array}{c}114 \\
(85.1)\end{array}$ & $\begin{array}{c}20 \\
(14.9)\end{array}$ & $\begin{array}{c}0 \\
(0)\end{array}$ & $\begin{array}{c}26 \\
(76.5)\end{array}$ & $\begin{array}{c}8 \\
(23.5)\end{array}$ & $\begin{array}{c}0 \\
(0)\end{array}$ \\
\hline Going to take relevant history before entry in OPD room? & $\begin{array}{c}134 \\
(94.4)\end{array}$ & $\begin{array}{c}6 \\
(4.2)\end{array}$ & $\begin{array}{c}2 \\
(1.4)\end{array}$ & $\begin{array}{c}124 \\
(92.5)\end{array}$ & $\begin{array}{c}10 \\
(7.5)\end{array}$ & $\begin{array}{c}0 \\
(0)\end{array}$ & $\begin{array}{c}32 \\
(94.1)\end{array}$ & $\begin{array}{c}2 \\
(5.9)\end{array}$ & $\begin{array}{c}0 \\
(0)\end{array}$ \\
\hline Thermal screening of patient before entry in OPD room? & $\begin{array}{c}118 \\
(83.1)\end{array}$ & $\begin{array}{c}22 \\
(15.5)\end{array}$ & $\begin{array}{c}2 \\
(1.4)\end{array}$ & $\begin{array}{c}96 \\
(71.6)\end{array}$ & $\begin{array}{c}38 \\
(28.4)\end{array}$ & $\begin{array}{c}0 \\
(0)\end{array}$ & $\begin{array}{c}28 \\
(82.4)\end{array}$ & $\begin{array}{c}6 \\
(17.6)\end{array}$ & $\begin{array}{c}0 \\
(0)\end{array}$ \\
\hline $\begin{array}{l}\text { Sanitizing hands of patients before allowing them to } \\
\text { OPD room? }\end{array}$ & $\begin{array}{c}116 \\
(81.7)\end{array}$ & $\begin{array}{c}24 \\
(16.9)\end{array}$ & $\begin{array}{c}2 \\
(1.4)\end{array}$ & $\begin{array}{c}114 \\
(85.1)\end{array}$ & $\begin{array}{c}20 \\
(14.9)\end{array}$ & $\begin{array}{c}0 \\
(0)\end{array}$ & $\begin{array}{c}32 \\
(94.1)\end{array}$ & $\begin{array}{c}2 \\
(5.9)\end{array}$ & $\begin{array}{c}0 \\
(0)\end{array}$ \\
\hline Patients should wear a mask before entering OPD room? & $\begin{array}{c}142 \\
(100)\end{array}$ & $\begin{array}{c}0 \\
(0)\end{array}$ & $\begin{array}{c}0 \\
(0)\end{array}$ & $\begin{array}{l}130 \\
(97)\end{array}$ & $\begin{array}{c}4 \\
(3)\end{array}$ & $\begin{array}{c}0 \\
(0)\end{array}$ & $\begin{array}{c}34 \\
(100)\end{array}$ & $\begin{array}{c}0 \\
(0)\end{array}$ & $\begin{array}{c}0 \\
(0)\end{array}$ \\
\hline Using new prescription at each visit? & $\begin{array}{c}68 \\
(47.9)\end{array}$ & $\begin{array}{c}72 \\
(50.7)\end{array}$ & $\begin{array}{c}2 \\
(1.4)\end{array}$ & $\begin{array}{c}62 \\
(46.3)\end{array}$ & $\begin{array}{c}72 \\
(53.7)\end{array}$ & $\begin{array}{c}0 \\
(0)\end{array}$ & $\begin{array}{c}30 \\
(88.2)\end{array}$ & $\begin{array}{c}4 \\
(11.8)\end{array}$ & $\begin{array}{c}0 \\
(0)\end{array}$ \\
\hline Avoid physical examination unless very necessary? & $\begin{array}{l}132 \\
(93)\end{array}$ & $\begin{array}{c}8 \\
(5.6)\end{array}$ & $\begin{array}{c}2 \\
(1.4)\end{array}$ & $\begin{array}{c}114 \\
(85.1)\end{array}$ & $\begin{array}{c}20 \\
(14.9)\end{array}$ & $\begin{array}{c}0 \\
(0)\end{array}$ & $\begin{array}{c}34 \\
(100)\end{array}$ & $\begin{array}{c}0 \\
(0)\end{array}$ & $\begin{array}{c}0 \\
(0)\end{array}$ \\
\hline $\begin{array}{l}\text { Sanitizing of consultation room before attending next } \\
\text { patient? }\end{array}$ & $\begin{array}{c}36 \\
(25.3)\end{array}$ & $\begin{array}{c}104 \\
(73.3)\end{array}$ & $\begin{array}{c}2 \\
(1.4)\end{array}$ & $\begin{array}{c}34 \\
(25.4)\end{array}$ & $\begin{array}{c}100 \\
(74.6)\end{array}$ & $\begin{array}{c}0 \\
(0)\end{array}$ & $\begin{array}{c}20 \\
(58.8)\end{array}$ & $\begin{array}{c}14 \\
(41.2)\end{array}$ & $\begin{array}{c}0 \\
(0)\end{array}$ \\
\hline $\begin{array}{l}\text { Unidirectional flow of OPD by maintaining separate entry } \\
\text { and exit point? }\end{array}$ & $\begin{array}{c}66 \\
(46.5)\end{array}$ & $\begin{array}{c}74 \\
(52.1)\end{array}$ & $\begin{array}{c}2 \\
(1.4)\end{array}$ & $\begin{array}{c}38 \\
(28.4)\end{array}$ & $\begin{array}{c}96 \\
(71.6)\end{array}$ & $\begin{array}{c}0 \\
(0)\end{array}$ & $\begin{array}{c}14 \\
(41.2)\end{array}$ & $\begin{array}{c}20 \\
(58.8)\end{array}$ & $\begin{array}{c}0 \\
(0)\end{array}$ \\
\hline $\begin{array}{l}\text { Consent will be taken from patient that he/she may get } \\
\text { infected by COVID-19? }\end{array}$ & $\begin{array}{c}118 \\
(83.1)\end{array}$ & $\begin{array}{c}22 \\
(15.5)\end{array}$ & $\begin{array}{c}2 \\
(1.4)\end{array}$ & $\begin{array}{c}94 \\
(70.1)\end{array}$ & $\begin{array}{c}36 \\
(26.9)\end{array}$ & $\begin{array}{c}4 \\
(3)\end{array}$ & $\begin{array}{c}18 \\
(53)\end{array}$ & $\begin{array}{c}16 \\
(47)\end{array}$ & $\begin{array}{c}0 \\
(0)\end{array}$ \\
\hline COVID -19 testing for every patient posted for surgery? & $\begin{array}{c}94 \\
(66.2)\end{array}$ & $\begin{array}{c}46 \\
(32.4)\end{array}$ & $\begin{array}{c}2 \\
(1.4)\end{array}$ & $\begin{array}{c}80 \\
(59.7)\end{array}$ & $\begin{array}{c}54 \\
(40.3)\end{array}$ & $\begin{array}{c}0 \\
(0)\end{array}$ & $\begin{array}{c}24 \\
(70.6)\end{array}$ & $\begin{array}{c}10 \\
(29.4)\end{array}$ & $\begin{array}{c}0 \\
(0)\end{array}$ \\
\hline $\begin{array}{c}\text { Perform HRCT chest in all patients with positive RT-PCR } \\
\text { or Antibody test for COVID-19? }\end{array}$ & $\begin{array}{c}66 \\
(46.5)\end{array}$ & $\begin{array}{c}76 \\
(53.5)\end{array}$ & $\begin{array}{c}0 \\
(0)\end{array}$ & $\begin{array}{c}72 \\
(53.7)\end{array}$ & $\begin{array}{c}58 \\
(43.3)\end{array}$ & $\begin{array}{c}4 \\
(3)\end{array}$ & $\begin{array}{c}16 \\
(50)\end{array}$ & $\begin{array}{c}16 \\
(50)\end{array}$ & $\begin{array}{c}2 \\
(5.9)\end{array}$ \\
\hline $\begin{array}{l}\text { Separate operation theatre to operate patients with } \\
\text { positive COVID-19 test? }\end{array}$ & $\begin{array}{c}106 \\
(74.7)\end{array}$ & $\begin{array}{c}34 \\
(23.9)\end{array}$ & $\begin{array}{c}2 \\
(1.4)\end{array}$ & $\begin{array}{c}94 \\
(70.1)\end{array}$ & $\begin{array}{c}34 \\
(25.4)\end{array}$ & $\begin{array}{c}6 \\
(4.5)\end{array}$ & $\begin{array}{c}22 \\
(64.7)\end{array}$ & $\begin{array}{c}10 \\
(29.4)\end{array}$ & $\begin{array}{c}2 \\
(5.9)\end{array}$ \\
\hline $\begin{array}{l}\text { Prefer open surgery over minimal invasive surgery for } \\
\text { positive COVID-19 patients? }\end{array}$ & $\begin{array}{c}92 \\
(64.8)\end{array}$ & $\begin{array}{c}46 \\
(32.4)\end{array}$ & $\begin{array}{c}4 \\
(2.8)\end{array}$ & $\begin{array}{c}78 \\
(58.2)\end{array}$ & $\begin{array}{c}56 \\
(41.8)\end{array}$ & $\begin{array}{c}0 \\
(0)\end{array}$ & $\begin{array}{c}28 \\
(82.4)\end{array}$ & $\begin{array}{c}6 \\
(17.6)\end{array}$ & $\begin{array}{c}0 \\
(0)\end{array}$ \\
\hline Easily getting good quality PPE? & $\begin{array}{c}72 \\
(50.7)\end{array}$ & $\begin{array}{c}68 \\
(47.9)\end{array}$ & $\begin{array}{c}2 \\
(1.4)\end{array}$ & $\begin{array}{c}88 \\
(65.7)\end{array}$ & $\begin{array}{c}46 \\
(34.3)\end{array}$ & $\begin{array}{c}0 \\
(0)\end{array}$ & $\begin{array}{c}30 \\
(88.2)\end{array}$ & $\begin{array}{c}4 \\
(11.8)\end{array}$ & $\begin{array}{c}0 \\
(0)\end{array}$ \\
\hline $\begin{array}{l}\text { Random sampling of healthcare workers involved in } \\
\text { patient care? }\end{array}$ & $\begin{array}{c}82 \\
(57.8)\end{array}$ & $\begin{array}{c}56 \\
(39.4)\end{array}$ & $\begin{array}{c}4 \\
(2.8)\end{array}$ & $\begin{array}{c}68 \\
(50.8)\end{array}$ & $\begin{array}{c}66 \\
(49.2)\end{array}$ & $\begin{array}{c}0 \\
(0)\end{array}$ & $\begin{array}{c}28 \\
(82.4)\end{array}$ & $\begin{array}{c}6 \\
(17.6)\end{array}$ & $\begin{array}{c}0 \\
(0)\end{array}$ \\
\hline $\begin{array}{c}\text { Repeat RT-PCR test before discharging patients after } \\
\text { surgery? }\end{array}$ & $\begin{array}{c}30 \\
(21.1)\end{array}$ & $\begin{array}{c}112 \\
(78.9)\end{array}$ & $\begin{array}{c}0 \\
(0)\end{array}$ & $\begin{array}{c}4 \\
(3)\end{array}$ & $\begin{array}{l}126 \\
(94)\end{array}$ & $\begin{array}{c}4 \\
(3)\end{array}$ & $\begin{array}{c}10 \\
(29.4)\end{array}$ & $\begin{array}{c}22 \\
(64.7)\end{array}$ & $\begin{array}{c}2 \\
(5.9)\end{array}$ \\
\hline
\end{tabular}

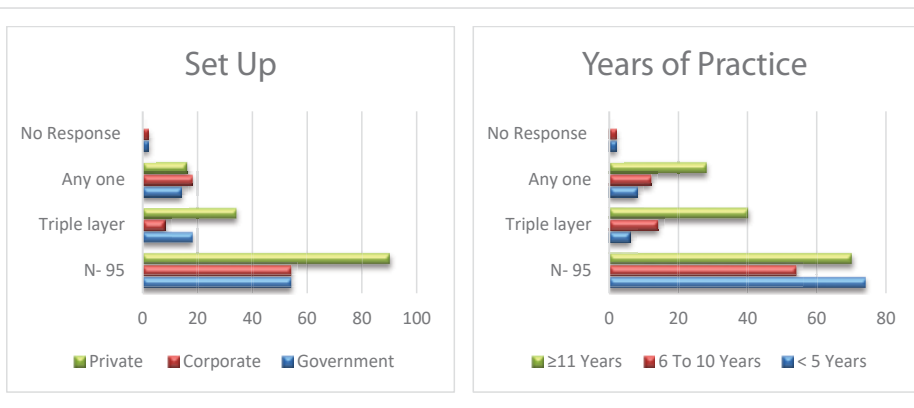

Age

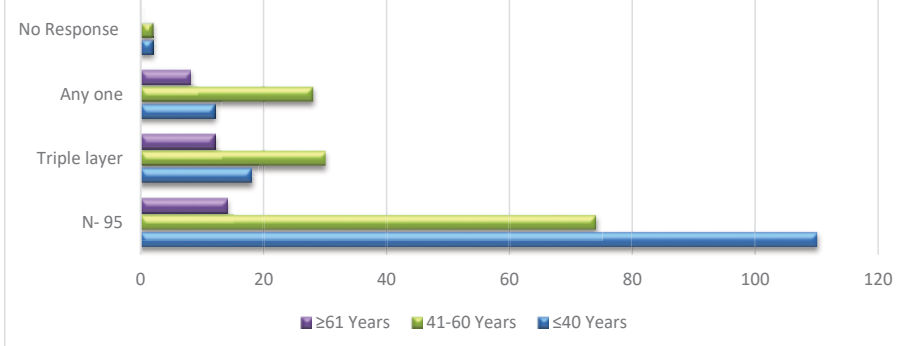


Table 6: Change in surgical practice.

\begin{tabular}{|c|c|c|c|c|c|c|c|}
\hline & & \multicolumn{2}{|c|}{ All surgeries as previous } & \multicolumn{2}{|c|}{ Only emergency surgeries } & \multicolumn{2}{|c|}{ Emergency surgeries and malignancy cases } \\
\hline & & N (58) & $\%(18.7)$ & $\mathbf{N}(68)$ & $\%(21.9)$ & $\mathbf{N}(184)$ & $\%(59.4)$ \\
\hline \multirow{3}{*}{ Set-up } & Government (88) & 0 & 0 & 26 & 29.5 & 62 & 70.5 \\
\hline & Corporate (82) & 14 & 17.1 & 10 & 12.2 & 58 & 70.7 \\
\hline & Private (140) & 46 & 32.8 & 32 & 22.9 & 62 & 44.3 \\
\hline \multirow{3}{*}{ Years of practice } & $<5$ Years $(90)$ & 14 & 15.5 & 16 & 17.8 & 60 & 66.7 \\
\hline & 6 To 10 Years (82) & 22 & 26.8 & 8 & 9.8 & 52 & 63.4 \\
\hline & $\geq 11$ Years(138) & 22 & 15.9 & 44 & 31.9 & 72 & 52.2 \\
\hline \multirow{3}{*}{ Age } & $\leq 40$ Years $(142)$ & 30 & 21.1 & 16 & 11.3 & 96 & 67.6 \\
\hline & 41-60 Years(134) & 24 & 17.9 & 38 & 28.4 & 72 & 53.7 \\
\hline & $\geq 61$ Years (34) & 4 & 11.8 & 14 & 41.2 & 16 & 47 \\
\hline
\end{tabular}

Investigations preferred for COVID-19 testing

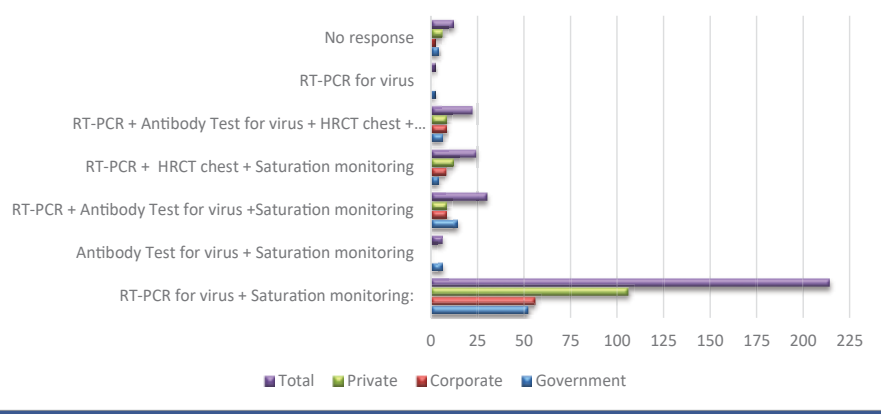

Table 7: Investigations preferred for COVID-19 testing.

and participants in the age group of $\leq 40$ years were more comfortable with N-95 masks.

As shown in table 6, majority (81.3\%) participant admitted to changing surgical practice, whereas the rest $(18.7 \%)$ was continuing their practice as before. The majority of them (59.4\%) agreed on performing emergency surgeries and malignancy cases, whereas $21.9 \%$ wanted to perform only emergency surgeries till risk of COVID-19 is minimized to an acceptable level. None in government setup was continuing surgical practice as previous, whereas $32.1 \%$ in private setup and $17.1 \%$ in a corporate setup were continuing surgeries as previous. Also, only $11.8 \%$ of participants with age $\geq 61$ years were continuing surgical practice as previous in comparison to $17.9 \%$ participants with age between $41-60$ years and $21.1 \%$ participants with age $\leq 40$ years.

As shown in table 7, the majority (69\%) agreed as RTPCR for virus plus saturation monitoring as preferred investigations for COVID-19 testing, whereas 9.7\% agreed on above tests plus antibody test for viruses. $7.7 \%$ wanted to do a HRCT chest in addition to RT-PCR and saturation monitoring, whereas $7.1 \%$ concluded on utilizing all the options including RT-PCR, saturation monitoring, HRCT chest and antibody test for the virus. Only $1.9 \%$ opted for antibody test and saturation monitoring, whereas only $0.7 \%$ opted for RT-PCR only. The majority in private setup (75.7\%) were happy with RT-PCR for virus plus saturation monitoring, whereas a significant percentage in government setup also wants to add an antibody test with above tests.

Regarding hike in surgical charges in view of extra cost incurred due to COVID-19 testing and PPE, 53.7\% participants in corporate setup and $58.6 \%$ in private setup responded with yes.

\section{Discussion}

This recent pandemic created lot of dilemma for urologists and their patients significantly affecting patientcare. There are various reasons which changed the practice pattern of urologists working in different setups. ${ }^{3,4}$ In many hospitals, elective surgeries have been postponed to prevent unnecessary exposure to these patients. Further, shunting of staff and resources has been done for better management of patients with coronavirus leading to scarcity of staff and resources for routine cases. Even, Influx of patients has been reduced due to government restrictions, decreased transport facilities and fear of getting infected [3-5]. The majority in every set-up in our survey admitted that their practice was affected due to the recent outbreak.

The majority admitted to attend patients with prior appointment or to attend a fixed number of patients and also to maintain detailed records of all patients, attendants and hospital visitors. The prior appointments reduce over-crowding in OPD and also decrease waiting period of patients in OPD area. The detailed records help to contact the required person if the need arises [7]. Also, the majority agreed on avoiding to enter attendees with patients in OPD unless necessary to avoid exposure to an extra person.

Huang, et al. noticed that most common symptom in patients infected with coronavirus was fever (98\%), followed by cough (76\%) and myalgia (44\%) [8]. The patients can be requested to fill a printed questionnaire before entering OPD, which includes all relevant questions such as history of fever or chills, cough, difficult breathing, fatigue, headache, loss of smell or taste, sore throat, runny nose and gastrointestinal symptoms to know if we are dealing with any suspected cases. Other relevant history, such as recent travel, residence in containment zone or close contacts with any confirmed cases can also be elicited [9]. Thermal scanners can also be utilized to detect people with fever $[7,9]$. The majority agreed on eliciting a necessary history and thermal screening before attending patients in our survey. 
One minute exposure time with ethanol at a concentration between $62 \%$ and $71 \%$ significantly reduces coronavirus infectivity [10]. Thus, alcohol-based hand sanitizer can be used at entry point for hand hygiene, which is a simple, cheap and effective way to prevent the spread of infections $[10,11]$. Another potential source of spread of infection in OPD is contamination of frequent touch surfaces such as floor, table, chairs and examination tables. The recommended disinfectants such as $70 \%-90 \%$ ethanol or $0.1 \%$ sodium hypochlorite can be used on environmental surfaces to reduce infectivity [10-12]. Also, new prescription can be used at every visit to avoid touching old prescription with the patient, a probable potential source of infection as few studies suggested that the virus survives on papers for 4 to 5 days [12]. The majority agreed to sanitize hands of patients before allowing them to OPD room and for using the new prescription at each visit but majority were not agreed on sanitizing of the consultation room before attending next patient as it may be a time-consuming and cumbersome procedure. The participants in the age group of more than 61 years were more in favor of using the new prescription at each visit and sanitizing of the consultation room than others, probably due to their experience and safety concern.

Digital rectal examination (DRE) is an integral part of the physical examination in urology. The possible transmission of the virus by aerosolized feces through fecal-oral or fecalrespiratory route after isolating the virus in feces has been mentioned, so DRE may be risky in the current situation [13]. The majority agreed on omitting physical examination unless necessary.

Unidirectional flow of patients can be maintained by using separate entry and exit point to avoid overcrowding. At the entry point, relevant history can be elicited and thermal scanners can be deployed. But, this may not possible in each setup due to restricted space or limited staff members [7]. The majority (190/310) were not in view of maintaining unidirectional flow.

Also in our survey, more participants from corporate and private setup in comparison to government setup were not agreed with maintaining the unidirectional flow probably in view of limited space and financial constraint.

Although N95 masks were found to be superior to triple layered masks in aspect of filter penetration and face-seal leakage, but definitive evidence are lacking to show decrease transmission rate of acute respiratory infections from patients to HCWs [14]. Doctors sitting in OPD must wear a mask at all times while attending patients at least a triple layered mask. Depending on availability and feasibility, an N95 mask should be used if practicing in a high risk zone [15]. The majority were in view of using N-95 masks during practice in our survey. Surprisingly, younger participant and less experienced were more in favor of using an N-95 mask, maybe they were more apprehensive or more cautious.
In urology, significant portions of patients are elderly with various co-morbidities making them highly susceptible to complications of COVID-19 [4]. Patients getting infected during OPD visits, surgery or during hospital stay and later developing complications may lead to medico-legal issues [16]. The majority agreed on taking a consent that patients may get infected by COVID-19 during or after a procedure or hospital stay. Surprisingly, more the experience, lesser they worried about consent, probably participants with lesser experience were more vigilant or afraid of medico-legal issues.

Various recommendations have been made to limit urological procedures to only emergency cases, such as high grade malignancies, obstructive uropathies and unstable trauma patients till risk of COVID-19 is minimized to an acceptable level [17]. The majority (184/310) in our survey were agreed with above made recommendations. The government setup was most affected and was performing only limited urological procedures, as many of them changed their priority to tackle this pandemic. Also, participants with age $\geq 61$ years were doing only limited urological procedures, probably due to safety concern.

There is a high prevalence of asymptomatic carriers functioning as spreaders of disease, so it is better to assume each and every patient COVID positive encountered. Various institutes are routinely doing COVID-19 testing for every patient posted for surgery, but various issues we can encounter in our practice may be financial concern, limited availability of testing kits and only a few centers performing this test [18]. A significant proportion (198/310) in our survey agreed on performing COVID - 19 test For every patient posted for surgery. Also, more urologists in the government setup were willing for COVID-19 testing for every patient posted for surgery in comparison to other, probably due to availability.

The patients posted for elective surgeries can be admitted 2 to 3 days prior in a separate ward and at least an RT-PCR test should be done. Also, preoperatively oxygen saturation and temperature monitoring can be performed till the day of surgery [19]. Few studies suggested that CT-scan of lung is a good technique to detect COVID-19 patients [19,20]. Even, some patients with a negative COVID-RT-PCR test may show abnormalities on lung CT-scan in infected cases. The combination of RT-PCR and lung CT-scan can give higher diagnostic sensitivity (92\%) in comparing to RT-PCR alone (78\%) and lung CT-scan alone (67\%), thus decreasing the risk of operating on an infected case [20,21]. The participants in a private setup were happy with RT-PCR plus saturation monitoring, whereas others want to add a few more tests also, the probable reason may be financial issues in private setup.

Ideally, elective surgeries should be postponed in 
COVID-19 positive patients until they turned negative for virus as there is higher morbidity and mortality in such patients after surgery. Also, a separate operation theatre should be dedicated to all positive or suspected COVID-19 patients needing emergency intervention, preferably situated in the designated COVID Block [18]. The majority agreed to assign separate operation theatre to operate patients with positive COVID-19 test.

There is a significant decrease in the number of open urological procedures due to various advances in minimal invasive techniques. The recent COVID-19 pandemic has led to some theoretical concerns regarding safety of robotic and laparoscopic techniques due to aerosol generation. Aerosols may be generated during desufflation of the pneumoperitoneum or during use of energy sources [22]. Some guidelines recommended for considering laparoscopy only in selected cases where clinical benefits outweigh the risk of potential viral transmission [23]. There are no conclusive evidences to demonstrate COVID-19 in the generated aerosol particles. Laparoscopy or robotic surgery is not absolutely contraindicated, but appropriate personal protective equipments (PPE) and smoke evacuation systems are recommended for safety $[22,23]$. There are some certain advantages of minimally invasive procedures. Advancement in ports used in robotic surgeries creates a more stable pneumoperitoneum and within the ports create a protective gas barrier preventing leaks [24]. Robotic surgery allows the chief surgeon to operate at an adequate distance from the patient and also allows comparatively better distancing between assistant surgeons. Even, laparoscopic surgery allows better social distancing between operating surgeons and assistants in comparison to open surgery [25]. A significant proportion in our survey (198/310) admitted to preferring open surgery over minimal invasive surgery (Laparoscopic/Robotic).

The participants with lesser experience ( $\leq 5$ years) and more experience ( $\geq 11$ years) preferred open surgery in comparison to participants with 6-10 years of experience, probably younger were cautious, seniors were wiser and participants with 6-10 years of experience were courageous.

Initially there were hurdles to get a good quality PPE due to the shortage, but India moved at a quick pace to become the second largest manufacturer in world PPE within a short span of time [26]. In our survey, a significant proportion $(190 / 310)$ responded positively about easily getting PPE kits. Participants with experience of $\leq 5$ years were struggling with getting good quality PPE in comparison to more experienced, probably they were new in field with relatively less contacts.

The viral load even in asymptomatic cases is similar to symptomatic cases, which indicates similar transmission potential of asymptomatic cases. Health care workers (HCWs) have a high risk for infection due to exposure and many of them may remain asymptomatic or have subtle symptoms. These asymptomatic HCWs may further spread disease to patients, co-workers, and family members. These asymptomatic cases should be identified early and isolated to avoid further spread of infection [27]. A good proportion $(178 / 310)$ agreed on random sampling of healthcare workers involved in patient care. The senior most participants $(\geq 61$ years) were more in favor of random sampling of healthcare workers involved in patient care.

Same as HCWs, patients stayed in hospital for surgery or any other reason may contract the infection and may remain asymptomatic leading to substantial risk to community after discharge. Also, the patients may claim to get infected during stay even if they got infected later on by some other source [28]. So, one question arose in our mind that should we conduct an RT-PCR test before discharging patients to safeguard the community and avoiding medico-legal issues, but the majority (260/310) were against it. We noticed that more urologists in the government setup were agreed to it in comparison to other, the probable reason may be limited resources or financial restraints in other setups.

Use of PPE, changed infection control strategy and need of doing COVID-19 testing in elective cases have led to increased expenditure on private and corporate setup. Also, there is fall in patient visits leading to decline in revenue generated [29]. The majority (126/222) admitted to increase surgical charges in view of extra cost incurred due to COVID-19 testing and PPE.

There are various limitations to this survey. We were not able to contact all of the urologists and many of the contacted urologists did not participate in this survey.

The strength of this survey is that it involves participants working in different setup and also with varying experience. This is the first survey based on Indian practice, which is a quite different kind of practice from other countries.

\section{Conclusion}

Our survey revealed that the recent pandemic led to significant impacts on urology practice in our country. The urologists working in different setups are facing different challenges in this difficult condition. They have made certain changes in their practice to safely provide effective care to their patients.

\section{References}

1. Zhang G, Zhang J, Wang B, Zhu X, Wang Q, et al. Analysis of clinical characteristics and laboratory findings of 95 cases of 2019 novel coronavirus pneumonia in Wuhan, China: a retrospective analysis. Respir Res. 2020; 21: 74.

PubMed: https://pubmed.ncbi.nlm.nih.gov/32216803/

2. Feng W, Zong W, Wang F, Ju S. Severe acute respiratory syndrome coronavirus 2 (SARS-CoV-2): a review. Mol Cancer. 2020; 19: 100. PubMed: https://pubmed.ncbi.nIm.nih.gov/32487159/ 
3. Devana SK, Chaudhary K, Sharma AP, Singh SK. Changing urological practice during COVID-19. Indian J Urol 2020; 36: 153-158. PubMed: https://pubmed.ncbi.nlm.nih.gov/33082628/

4. Gravas S, Bolton D, Gomez R, Klotz L, Kulkarni S, et al. Impact of COVID-19 on Urology Practice: A Global Perspective and Snapshot Analysis. J Clin Med. 2020; 9:E1730.

PubMed: https://pubmed.ncbi.nlm.nih.gov/32503305/

5. Teoh JY, Ong WLK, Gonzalez-Padilla D, Castellani D, Dubin JM, et al. A Global Survey on the Impact of COVID-19 on Urological Services. Eur Urol. 2020; 78: 265-275.

PubMed: https://pubmed.ncbi.nlm.nih.gov/32507625/

6. Goel A. Urology in India: Numbers and practice. Indian J Urol. 2019; 35: 245-247.

PubMed: https://pubmed.ncbi.nlm.nih.gov/31619860/

7. Sengupta S, Honavar SG, Sachdev MS, Sharma N, Kumar A, et al. All India Ophthalmological Society - Indian Journal of Ophthalmology consensus statement on preferred practices during the COVID-19 pandemic. Indian J Ophthalmol. 2020; 68: 711-724.

PubMed: https://pubmed.ncbi.nlm.nih.gov/32317433/

8. Huang C, Wang Y, Li X, Ren L, Zhao J, et al. Clinical features of patients infected with 2019 novel coronavirus in Wuhan, China. Lancet. 2020; 395: 497-506.

PubMed: https://pubmed.ncbi.nlm.nih.gov/31986264/

9. Hur J, Chang MC. Usefulness of an Online Preliminary Questionnaire under the COVID-19 Pandemic. J Med Syst. 2020; 44: 116.

PubMed: https://pubmed.ncbi.nlm.nih.gov/32430783/

10. Kratzel A, Todt D, V'kovski P, Steiner S, Gultom M, et al. Inactivation of Severe Acute Respiratory Syndrome Coronavirus 2 by WHORecommended Hand Rub Formulations and Alcohols. Emerg Infect Dis. 2020; 26: 1592-1595.

PubMed: https://pubmed.ncbi.nlm.nih.gov/32284092/

11. Lai CC, Shih TP, Ko WC, Tang HJ, Hsueh PR. Severe acute respiratory syndrome coronavirus 2 (SARS-CoV-2) and coronavirus disease-2019 (COVID-19): The epidemic and the challenges. Int J Antimicrob Agents. 2020 55: 105924.

PubMed: https://pubmed.ncbi.nlm.nih.gov/32081636/

12. Kampf G, Todt, D, Pfaender, S, Steinmann, E. Persistence of coronaviruses on inanimate surfaces and their inactivation with biocidal agents. J Hosp Infect. 2020; 104: 246-251.

PubMed: https://pubmed.ncbi.nlm.nih.gov/32035997/

13. Xu Y, Li X, Zhu B, Liang H, Fang C, et al. Characteristics of pediatric SARS-CoV-2 infection and potential evidence for persistent fecal viral shedding. Nat Med. 2020; 26: 502-505.

PubMed: https://pubmed.ncbi.nlm.nih.gov/32284613/

14. Smith JD, MacDougall CC, Johnstone J, Copes RA, Schwartz B, et al. Effectiveness of $\mathrm{N} 95$ respirators versus surgical masks in protecting health care workers from acute respiratory infection: a systematic review and meta-analysis. CMAJ. 2016; 188: 567-574.

PubMed:: https://pubmed.ncbi.nlm.nih.gov/26952529/

15. Agrawal H, Singh S, Gupta N. What All We Should Know about Masks in COVID-19 Pandemic. Indian J Surg. 2020; 1-2.

PubMed: https://pubmed.ncbi.nIm.nih.gov/32837071/

16. Bhattacharya N, Bhattacharya K. Informed Consent for Surgery during COVID-19. Indian J Surg. 2020; 1-3

PubMed: https://pubmed.ncbi.nlm.nih.gov/32390694/

17. Nowroozi A, Amini E. Urology practice in the time of COVID-19. Urol J. 2020; 17: 326

18. Malhotra N, Bajwa SJ, Joshi M, Mehdiratta L, Trikha A. COVID Operation Theatre- Advisory and Position Statement of Indian Society of Anaesthesiologists (ISA National). Indian J Anaesth. 2020; 64: 355362.

PubMed: https://www.ncbi.nlm.nih.gov/pmc/articles/PMC7286404/

19. Mouton C, Hirschmann MT, Ollivier M, Seil R, Menetrey J. COVID-19 - ESSKA guidelines and recommendations for resuming elective surgery. J Exp Orthop. 2020; 7: 28.

PubMed: https://pubmed.ncbi.nlm.nih.gov/32405872/

20. Jiang $M$, Chen $P, L i T$, Tang $Y$, Chen $X$, et al. Chest CT imaging features and clinical outcome of coronavirus disease 2019 (COVID-19): A singlecenter case study in Ningbo, China. Clin Imaging. 2020; 69: 27-32. PubMed: https://pubmed.ncbi.nlm.nih.gov/32652454/

21. Xie X, Zhong Z, Zhao W, Zheng C, Wang F, et al. Chest CT for Typical 2019-nCoV Pneumonia: Relationship to Negative RT-PCR Testing. Radiology. 2020; 296: E41-E45.

PubMed: https://pubmed.ncbi.nlm.nih.gov/32049601/

22. Condon B, Whish-Wilson T, Davis NF, Lawrentschuk N. Implications of COVID-19 on urological laparoscopic surgery. Future Oncol. 2020; 16: $1941-1945$

PubMed: https://pubmed.ncbi.nlm.nih.gov/32597203/

23. Moletta L, Pierobon ES, Capovilla G, Costantini M, Salvador R, et al. International guidelines and recommendations for surgery during Covid-19 pandemic: A Systematic Review. Int J Surg. 2020; 79: 180188. PubMed: https://pubmed.ncbi.nlm.nih.gov/32454253/

24. Horstmann M, Horton K, Kurz M, Padevit C, John H. Prospective comparison between the AirSeal ${ }^{\circledR}$ System valve-less Trocar and a standard Versaport ${ }^{\mathrm{TM}}$ Plus V2 Trocar in robotic-assisted radical prostatectomy. J Endourol. 2013; 27: 579-582.

PubMed: https://pubmed.ncbi.nlm.nih.gov/23186377/

25. Vigneswaran $Y$, Prachand VN, Posner MC, Matthews JB, Hussain M. What Is the Appropriate Use of Laparoscopy over Open Procedures in the Current COVID-19 Climate? J Gastrointest Surg. 2020; 24: 1686-1691.

PubMed: https://pubmed.ncbi.nlm.nih.gov/32285338/

26. Sureka B, Sinha A, Tak V, Garg MK, Bhatia PK, et al. Customized personal protective equipment (PPE): Solution to conservation and management of supplies during the coronavirus disease 2019 (COVID-19) pandemic. J Family Med Prim Care. 2020; 9: 2180-2182. PubMed: https://pubmed.ncbi.nlm.nih.gov/32754469/

27. Lai X, Wang M, Qin C, Tan L, Ran L, et al. Coronavirus Disease 2019 (COVID-2019) Infection Among Health Care Workers and Implications for Prevention Measures in a Tertiary Hospital in Wuhan, China. JAMA Netw Open. 2020; 3: e209666.

PubMed: https://pubmed.ncbi.nlm.nih.gov/32437575/

28. Nagpal N. Emerging Medico-legal Issues Novel to COVID Era. J Digest Endosc. 2020; 11: 87-88.

PubMed: https://www.ncbi.nlm.nih.gov/pmc/articles/PMC7295274/

29. Khullar D, Bond AM, Schpero WL. COVID-19 and the Financial Health of US Hospitals. JAMA. 2020; 323: 2127-2128.

PubMed: https://pubmed.ncbi.nlm.nih.gov/32364565/ 